\title{
Atopic Dermatitis and Skin Fungal Microorganisms
}

\author{
Takashi Sugitaㄹ, Enshi Zhang ${ }^{3}$, Takafumi Tanaka1, Mami Tajima ${ }^{3}$, \\ Ryoji Tsuboi ${ }^{3}$, Yoshio Ishibashi², Akemi Nishikawa ${ }^{2}$ \\ ${ }^{1}$ Department of Microbiology, Meiji Pharmaceutical University, Kiyose, Tokyo \\ ${ }^{2}$ Department of Immunobiology, Meiji Pharmaceutical University, Kiyose, Tokyo \\ ${ }^{3}$ Department of Dermatology, Tokyo Medical University, Shinjuku, Tokyo \\ Japan
}

\section{Introduction}

A wide variety of bacteria and fungi are found on the human skin. Although some skin microorganisms produce antibacterial peptides that inhibit invasion by pathogens or promote the integrity of cutaneous defenses by eliciting host immune responses, the normal microbiome can also cause several skin diseases.

Atopic dermatitis (AD) is a chronic disease that causes pruritus and involves cycles of remission and deterioration. AD is the result of dry hypersensitive skin. When the skin is dry, the protective barrier function of the cutaneous surface horny layer is compromised, and the skin readily develops dermatitis in response to various external stimuli, including skin microorganisms. Serum from almost all AD patients contains IgE antibodies against some skin microorganisms. For example, staphylococcal superantigen-specific IgE is present in the serum of $\mathrm{AD}$ patients, but not in the serum of healthy individuals. Normally, the weakly acidic condition of healthy skin prevents colonization by Staphylococcus aureus. However, in patients with $\mathrm{AD}$, the skin $\mathrm{pH}$ is shifted toward neutrality, allowing S. aureus to grow and exacerbate AD.

In the cutaneous fungal microbiome, lipophilic yeasts of the genus Malassezia are the predominant species on human skin. As Malassezia species require lipids for growth, they preferentially colonize sebum-rich areas such as the head, face, and neck, as opposed to the limbs or trunk. Specific IgE antibody against Malassezia species is found in the serum of AD patients. Antifungal therapy improves the symptoms of AD by decreasing the level of Malassezia colonization, suggesting that these microorganisms also exacerbate AD. Malassezia species, unlike $S$. aureus, colonize both AD patients and healthy subjects. Currently, the genus Malassezia consists of 14 species. Of these, M. globosa and M. restricta have been detected in almost all AD patients, suggesting that these two Malassezia species play a significant role in AD. The level of specific $\operatorname{IgE}$ antibody against both species is greater than that against other Malassezia species.

This chapter discusses cutaneous fungi as an exacerbating factor in $\mathrm{AD}$, focusing on:

- the fungal microbiome in patients with AD.

- immunological aspects of fungal colonization, and

- $\quad$ treatment with antifungal agents. 


\section{The fungal microbiome in patients with atopic dermatitis}

\subsection{Colonization by the fungus Malassezia in patients with atopic dermatitis}

The lipophilic yeast Malassezia is the predominant fungus on human skin. Morphologically, these microorganisms are ovoid, elongate, and cylindrical (Fig. 1). Their genome is smaller than that of other fungi ( $\mathrm{Xu}$ et al. 2007). As Malassezia species require lipids for growth, they preferentially colonize sebum-rich areas such as the head, face, or neck, rather than the limbs or trunk. Specific IgE antibodies against Malassezia are present in the serum of patients with $\mathrm{AD}$, and antifungal therapy can improve the symptoms of $\mathrm{AD}$ by decreasing the degree of colonization by Malassezia; thus, this fungus is believed to be an exacerbating factor in $\mathrm{AD}$ (more details are provided in a later chapter). In contrast to S. aureus, Malassezia species colonize both $\mathrm{AD}$ patients and healthy individuals. In addition to AD, Malassezia species are responsible for seborrheic dermatitis, folliculitis, and ptiryasis versicolor (Gupta et al. 2004; Ashbee 2007). Currently, 14 species are recognized within the genus Malassezia (Table 1), and five of these (M. caprae, M. cuniculi, M. equina, M. nana, and M. pachydermatis) show affinity for nonhuman animals.

\begin{tabular}{llc}
\hline Host & \multicolumn{1}{c}{ Species } & $\begin{array}{c}\text { Species implicated in skin } \\
\text { disease in human }\end{array}$ \\
\hline Human associated species & Malassezia dermatis & AD \\
& Malassezia furfur & SI \\
& Malassezia globosa & AD, SD, PV \\
& Malassezia japonica & \\
& Malassezia obtusa & \\
& Malassezia slooffiae & AD, SD \\
& Malassezia sympodialis & AD, SD, PV \\
& Malassezia restricta & \\
& Malassezia yamatoensis & \\
Nonhuman animal associated & Malassezia caprae & \\
species & Malassezia cuniculi & \\
& Malassezia equina \\
& Malassezia nana \\
& Malassezia \\
pachydermatis &
\end{tabular}

$\mathrm{AD}$, atopic dermatitis; $\mathrm{SD}$, seborrheic dermatitis; SI, systemic infection; $\mathrm{PV}$, pityriasis versicolor Table 1. Currently accepted Malassezia species

A number of epidemiological studies have been conducted during the past decade to elucidate the role of Malassezia as an exacerbating factor in AD. The first was carried out by Nakabayashi et al. (2000) in Japan and detected M. furfur, M. globosa, M. sympodialis, and M. 
slooffiae in $21.4,14.3,7.1$, and $3.6 \%$ of samples from Japanese AD patients, respectively. A study conducted in Sweden in 2005 produced similar results (Sandström et al. 2005). However, a Canadian study by Gupta et al. (2001) reported the predominant species to be $M$. sympodialis, which was detected in $51.3 \%$ of the samples from AD patients. All of these studies were performed using culture-dependent methods. In all cases, scale samples were collected by an appropriate method, e.g., swabbing, scratching, or stripping, and were incubated in medium containing several types of fatty acids. The recovered microorganisms were identified based on biochemical or physiological characteristics, including assimilation of Tween compounds and esculin, catalase reaction, and maximum growth temperature (Guého-Kellermann 2010; Kaneko et al. 2007). However, culture-dependent methods may not provide accurate and reliable results for Malassezia. The efficiency of culturing Malassezia strains depends on the isolation medium used, and the growth of some species, such $M$. obtusa and M. restricta, is slower than that of others.

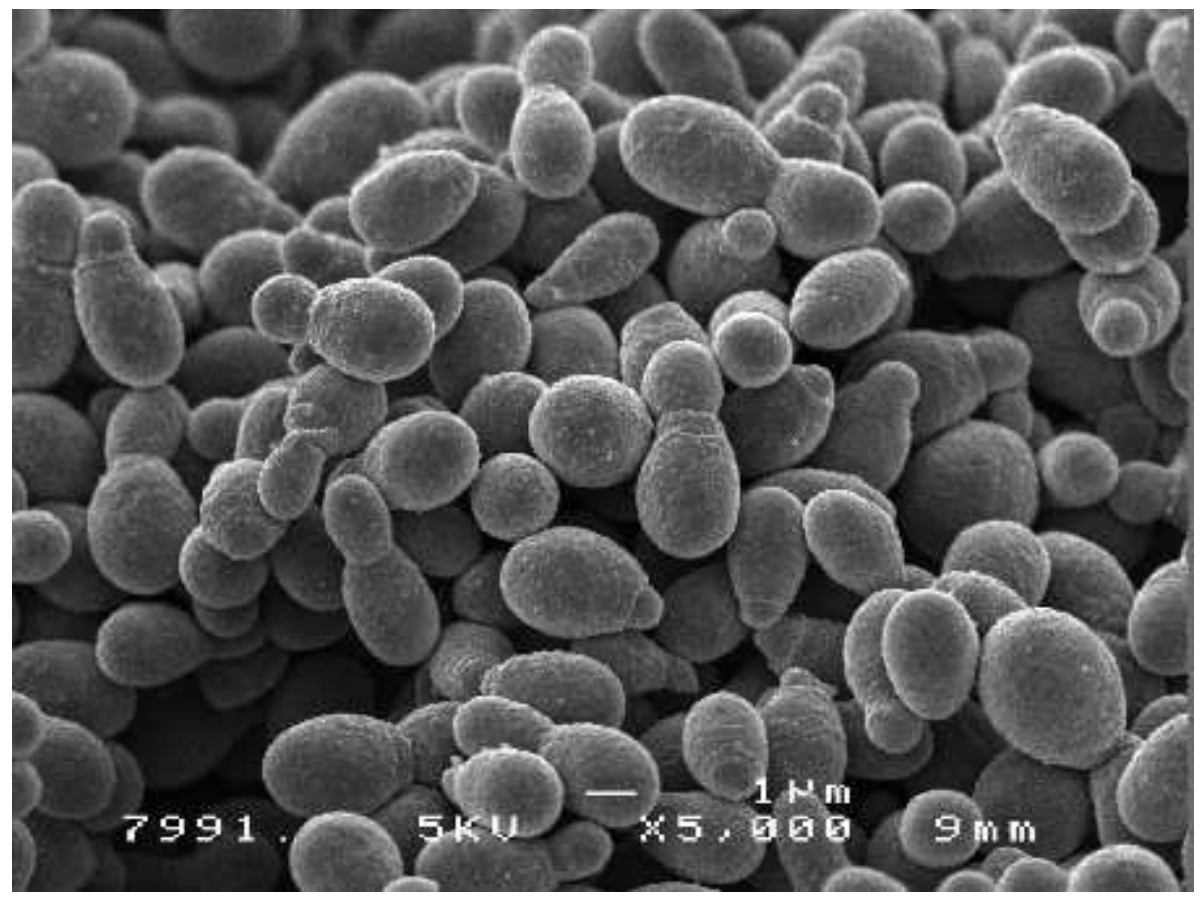

Magnification is $\times 5,000$.

Fig. 1. Morphology of Malassezia restricta by scanning electron microscope

To overcome the difficulties of culture-dependent methods, including scale sampling methods, culturing conditions, and isolation techniques, Sugita et al. (2001) developed the first molecular analytical method for Malassezia. For this method, scale samples are collected by stripping with medical transparent dressing, and skin Malassezia DNA is directly extracted from the dressing. The Malassezia microbiota is then analyzed by realtime PCR, specific detection by PCR with a species-specific primer, or an rRNA clone method (Sugita et al. 2011). Although more expensive than culture-dependent methods, a 
molecular-based, non-culture approach appears to be the most reliable and appropriate for analysis of the skin Malassezia microbiota (Sugita et al. 2001; Morishita et al. 2006; Takahata et al. 2007a, 2007b; Tajima et al. 2008; Amaya et al. 2007). In all scale samples from AD patients, both $M$. globosa and $M$. restricta were detected by the molecular-based method, with the level of colonization by M. restricta being approximately 1.6 times that of M. globosa (Sugita et al. 2006a). Malassezia sympodialis was the second most predominant species (detected in 58\% of the cases), and M. dermatitis, M. furfur, M. obtusa, and $M$. slooffiae were detected in less than $30 \%$ of the cases (Fig. 2). These results suggest that both M. globosa and M. restricta may significantly exacerbate AD.

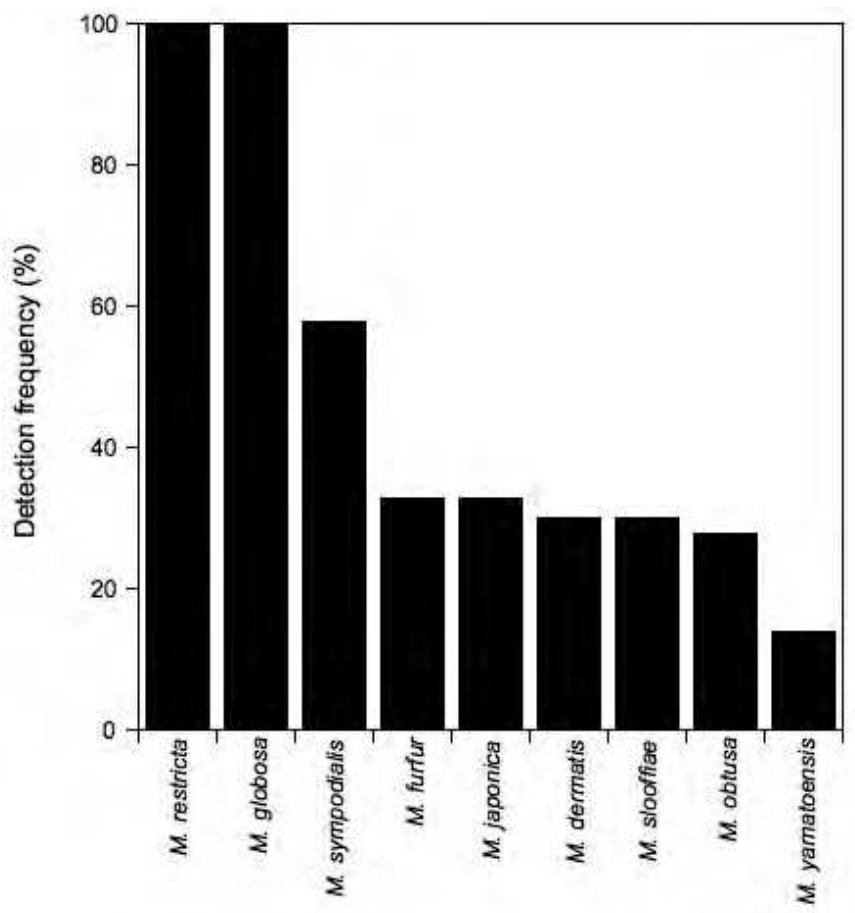

Malassezia DNA was detected by nested PCR assay with species-specific primers

Fig. 2. Colonization frequency of Malassezia in the scale of patient with atopic dermatitis

Given that $M$. globosa and $M$. restricta commonly colonize both AD patients and healthy individuals, specific genotypes of these microorganisms may play a role in AD (Sugita et al. $2003,2004,2010$ ). The fungal rRNA gene consists of four subunits: 5S, 5.8S, $18 S$ (small), and $26 S$ (large). Located between the subunits are an internal transcribed spacer (ITS) and an intergenic spacer (IGS). In M. globosa, the IGS is 444 to $454 \mathrm{bp}$ long and has four short sequence repeats (SSRs), $(\mathrm{CT} 1)_{\mathrm{n}},(\mathrm{CT} 2)_{\mathrm{n}},(\mathrm{CT} 3)_{\mathrm{n}}$, and $(\mathrm{GT})_{\mathrm{n}}$, which occur at positions 29-49, 278-291, 380-485, and 242-267, respectively, in the IGS sequence of M. globosa strain CBS 7996. Alignments of IGS 1 sequences of two M. globosa strains are shown in Fig. 3. The number of $(C T)_{n}$ SSRs in the IGS 1 region is more variable in samples from healthy individuals than in those from AD patients. In samples from $\mathrm{AD}$ patients, the number of sequence repeats in the IGS 1 region 
ranged from 4 to 11 for $(\mathrm{CT} 1)_{\mathrm{n}}, 3$ to 10 for $(\mathrm{CT} 2)_{\mathrm{n}}$, and 3 to 11 for $(\mathrm{CT} 3)_{\mathrm{n}}$, with $4(\mathrm{CT} 1)_{\mathrm{n}}$ repeats in $50 \%$ of the samples, $8(\mathrm{CT} 2)_{\mathrm{n}}$ in $60 \%$, and $9-11(\mathrm{CT} 3)_{\mathrm{n}}$ in $80 \%$. For $(\mathrm{GT})_{\mathrm{n}}$, the respective numbers of repeats in 70-80\% of the SSRs in the IGS 1 region were 9-11 in samples from AD patients and 15-19 in samples from healthy individuals. A phylogenetic tree constructed from 52 IGS 1 sequences is shown in Fig. 4. The tree consists of four major groups, which correspond to the sources of the samples (AD patients or healthy individuals). Two groups are from AD patients, and one is from healthy individuals. The remaining group included samples from both AD patients and healthy individuals. The IGS 1 sequences were more diverse in the samples from healthy individuals compared with AD patients. The IGS 1 sequence similarity was $94.5 \pm 3.5 \%$ among the $\mathrm{AD}$ patient samples and $89.9 \pm 3.5 \%$ among the samples from healthy individuals. The IGS 1 sequences of $M$. restricta are divided into two major groups, corresponding to AD patients and healthy individuals.

\section{GTGCATACCACACTCGAGCGCTTCTCTCTCTCTCTCTCT CT1 \\ CTCTCTGTGAGCGAGGCAATGGAGGTGTGTACCTCCAAC}

ACACCATCGCCCCAGGTACAGCCAATGGAGGTGTGTGTG

CGCGCTCCGGTTCCGCTCTCTTCTCGTACGCTTGGCTTC

GGATTCTCTCTCTCCTACGTACTGTGTGTGTGTGTGTGI

GT

GTGTGTGTGTGTGTGTGTGTGGATCTATGTCTCTCTCTC

CT2

TTTCTCCTTCAAATGGAGGTGTGTGTGCACCCTCACCCT

CGCCCTCGCTCACCCCCTCCTTTCCCATTCCCTTTTCCC

TATACCССтстстстстстстст

$\mathrm{CT} 3$

Fig. 3. DNA sequences of the IGS 1 region of M. globosa.

\subsection{Malassezia colonization and severity of AD}

The Malassezia microbiota of the skin is also associated with the severity of AD. Fifty-six adult neck and head AD patients ( 21 mild, 18 moderate, and 17 severe cases) and 32 healthy individuals were examined for skin Malassezia microbiota, using a real-time PCR assay (Kaga et al. 2011). The level of colonization by Malassezia was almost identical among the mild and moderate AD patients and the healthy individuals, while Malassezia colonization in the severe $\mathrm{AD}$ cases was approximately 2- to 5-fold that in the mild and moderate $\mathrm{AD}$ patients and healthy individuals (Fig. 5A). Two major species, M. globosa and M. restricta, accounted for more than $80 \%$ of all Malassezia colonization in AD patients of all severities, but their proportions differed with severity. In the mild and moderate cases, M. restricta predominated over M. globosa $(p<0.05)$, whereas the proportions of $M$. globosa and $M$. restricta were almost identical $(p>0.05)$ in the severe patients (Fig. 5B). 

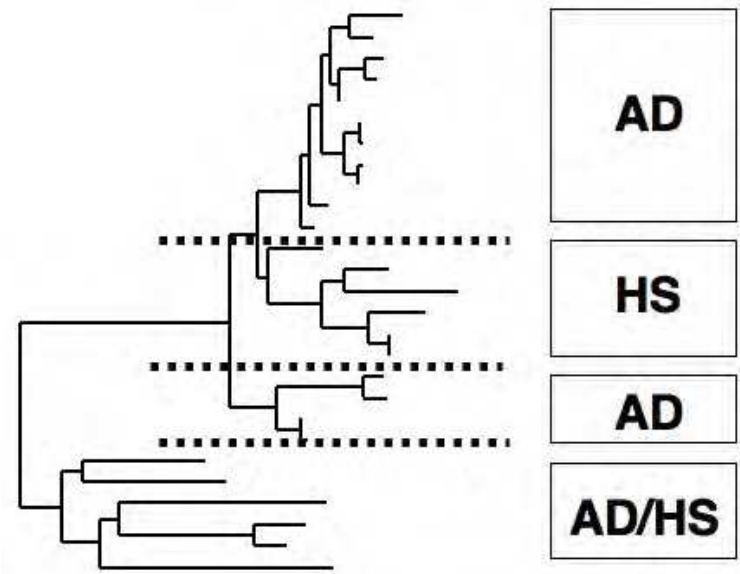

$\mathrm{AD}$, patients with atopic dermatitis; $\mathrm{HS}$, healthy subjects.

Fig. 4. Phylogenetic tree of M. globosa colonizing the skin surface of AD patients and healthy subjects based on DNA sequences of the IGS 1 region
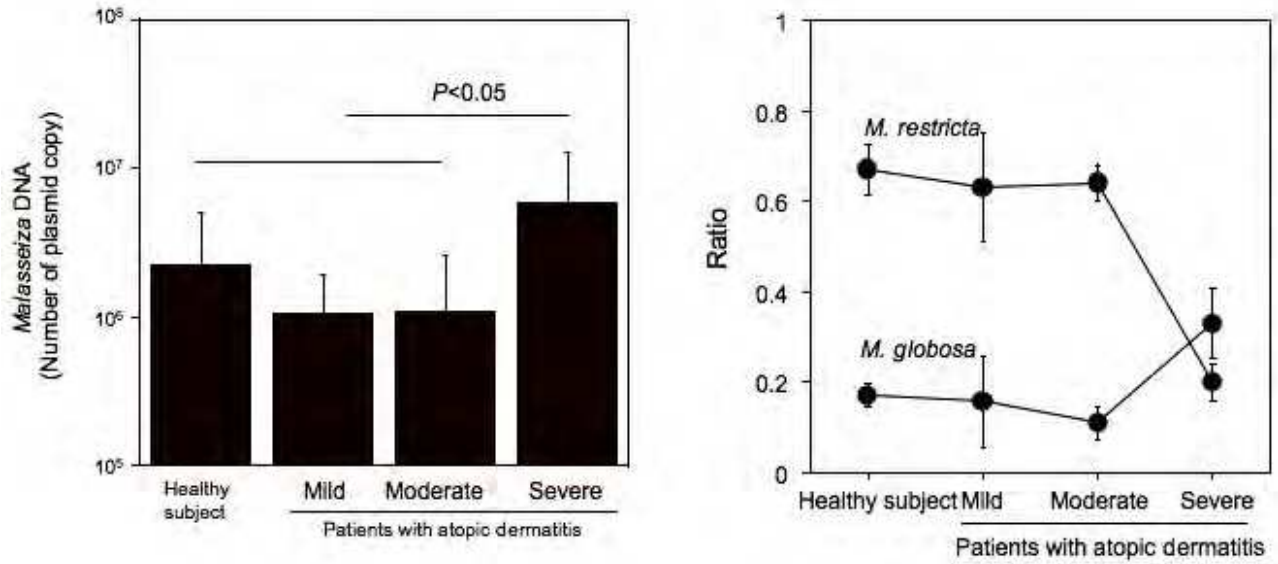

Fig. 5. Level of Malassezia colonization in patients with atopic dermatitis and in healthy individuals (A). Ratio of the two major Malassezia species, M. globosa and M. restricta, in patients with atopic dermatitis and in healthy individuals (B)

In a comprehensive analysis using an rRNA gene clone library method, Zhang et al. (2011) found that not only Malassezia but also the overall fungal microbiota differed according to AD severity. Their analysis of 3,647 clones of the fungal rRNA gene in scale samples from nine AD patients ( 3 mild, 3 moderate, and 3 severe cases) and 10 healthy individuals revealed 58 fungi and seven unknown phylotypes. Malassezia predominated, representing $63-86 \%$ of the clones identified from each subject. The number of clones had no noticeable relationship to disease severity, with the mild, moderate, and severe cases accounting for $67.8 \pm 2.2,70.7 \pm 2.8$, and $64.9 \pm 1.8 \%$ of the clones, respectively. The study also confirmed 
that both $M$. globosa and $M$. restricta were the predominant species regardless of disease severity, with a detection rate of $57.5-70.4 \%$ in all clones analyzed. However, the ratio of $M$. globosa to $M$. restricta in the mild and moderate cases (M. restricta/M. globosa: 3.1-3.4 in mild and 2.1-4.1 in moderate cases) differed from that in the severe cases (1.1-1.4). Figure 6 shows the phylogenetic distribution between AD patients and healthy individuals, based on principal coordinates analysis. Patients with mild or moderate symptoms of AD constituted a single cluster, and patients with severe disease formed a separate cluster. Similarly, the healthy individuals clustered independently.

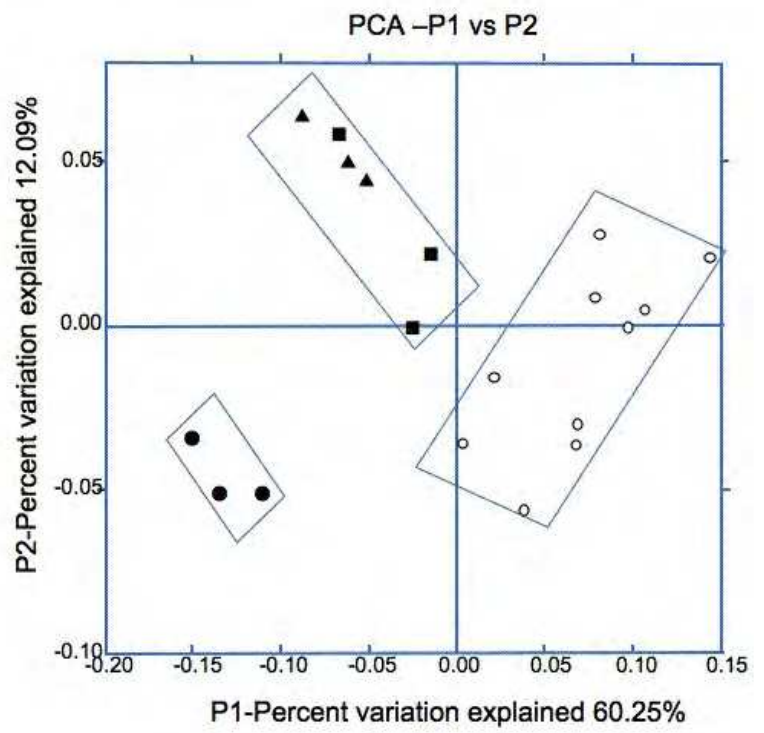

Closed triangle, patients with mild symptoms; closed square, patient with moderate symptoms; closed circle, patients with severe symptoms; open circle, healthy individuals

Fig. 6. Principal coordinates analysis (PCA) score plot of the sequence profiles for the predominant skin fungi

Differences in microbiota are thought to be attributable to differences in the physiological condition of the skin between patients with $\mathrm{AD}$ and healthy subjects. For example, skin $\mathrm{pH}$ may change skin microbiota (Seidenari and Giusti, 1995). Staphylococcus epidermidis is present in the skin microbiota of healthy individuals, whereas $S$. aureus is not. The level of colonization by $S$. aureus increases according to the severity of AD. In contrast, the level of colonization by $S$. epidermidis decreases gradually with increasing AD severity. Healthy skin is weakly acidic, whereas the skin $\mathrm{pH}$ in patients with AD is near neutral, which facilitates invasion by exogenous microorganisms, including S. aureus (Higaki et al. 1999; Hoeger et al. 1992). The expression levels of antimicrobial peptides may also affect the fungal microbiota (Howell 2007). The antimicrobial peptides known as defensins and cathelicidins are deficient in the skin of AD patients, and thus the fungal microbiota should be different between AD patients and healthy individuals. Sebum is a growth medium for skin microorganisms and consists of squalene, cholesterol esters, wax esters, triglycerides, free fatty acids, cholesterol, ceramides, cholesterol sulfate, and phospholipids. Of these, the 
proportion of ceramide 1, which is a carrier of linoleate and responsible for the water-barrier function of the skin, is significantly lower in patients with AD (Yamamoto et al. 1991). Therefore, the composition of sebum may also affect the fungal microbiota.

\section{Immunological aspects of Malassezia colonizaiton}

\subsection{Malassezia specific IgE antibody}

Specific IgE antibodies against skin Malassezia are present in the serum of AD patients whereas no anti-Malassezia specific IgE antibody is found in the serum of healthy individuals (Sugita et al. 2001). Many studies have reported on anti-Malassezia specific IgE antibodies in AD patients (Zargari et al. 2003; Kato et al. 2006). Using an enzyme-linked immunosorbent assay (ELISA), Kato et al. (2006) quantified specific IgE antibodies against soluble proteins of eight Malassezia species in mechanically disrupted extracts of serum samples from $\mathrm{AD}$ patients. The level of $\mathrm{IgE}$ specific for $M$. restricta was greater than that against other Malassezia species ( $M$. dermatis, M. furfur, M. globosa, M. obtusa, $M$. pachydermatis, M. slooffiae, and M. sympodialis) (Fig. 7); however, a competitive inhibition ELISA revealed that $M$. restricta contained species-specific as well as shared antigens.

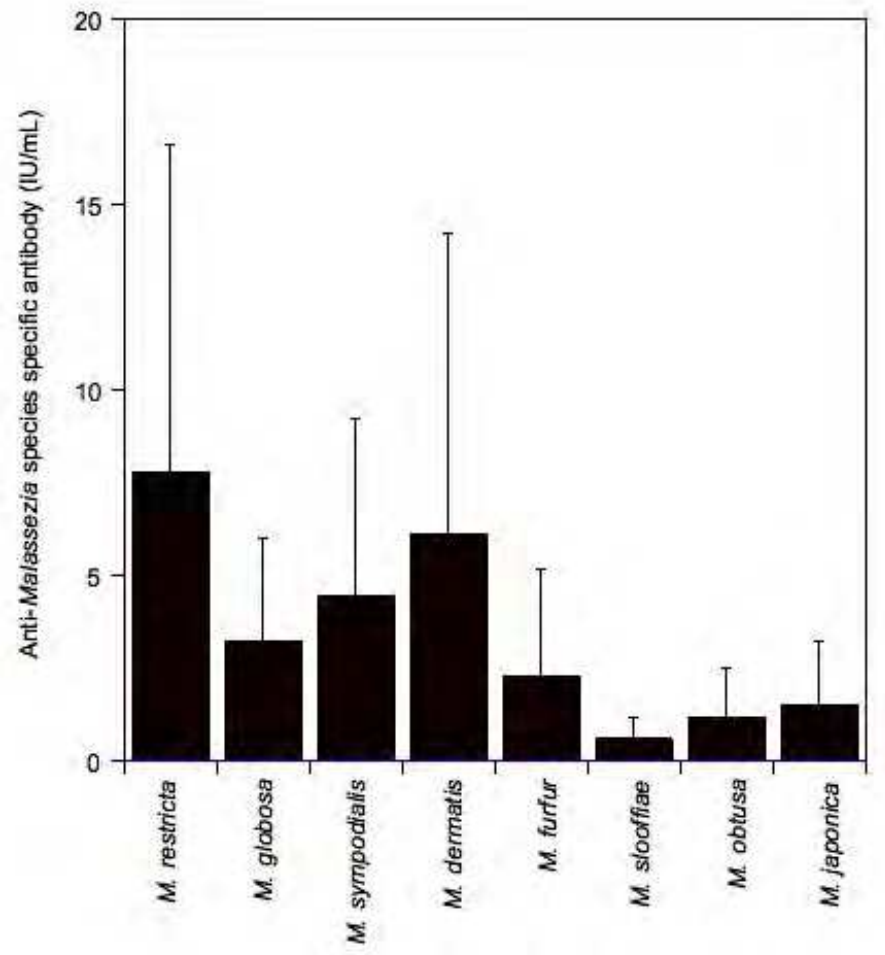

$\mathrm{N}=24$

Fig. 7. The species-specific IgE values of eight Malassezia species in sera from patients with atopic dermatitis determined using an ELISA. 
The precise mechanisms by which Malassezia colonization induces IgE antibody production and the inflammatory cascades that lead to $\mathrm{AD}$ remain unclear. The presence of $\mathrm{IgE}$ antibodies has been implicated in the production of Th2-type cytokines such as interleukins (IL)-4, -5, -6, -10, and -13, the promotion of IgE antibody production, the differentiation of mast cells, and the growth, migration, and activation of eosinophils (Hamid et al. 1994; Leung et al. 2000; Chen et al. 2004). Keratinocytes, the major cell type in the epidermis, have roles in both skin structural and immunological defense (Esche et al. 2004; Albanesi et al. 2005). Keratinocytes produce a range of proinflammatory and immune cytokines in response to microorganisms and/or skin damage (Grone et al. 2002; Watanabe et al. 2001). A recent study has demonstrated that keratinocytes secrete several Th2-type cytokines that are critical in the pathogenesis of AD (Ishibashi et al. 2006). Cytokine secretion profiling by antibody array analysis has revealed that $M$. globosa and $M$. restricta induce the secretion of distinct Th2-type cytokines by human keratinocytes: $M$. globosa induces IL-5, IL-10, and IL13 secretion, while $M$. restricta induces IL- 4 secretion. These findings have been confirmed by cDNA microarray analysis showing that $M$. globosa and $M$. restricta upregulate the transcription of the IL-5 and IL-4 genes, respectively, in keratinocytes. These observations provide evidence of a possible relationship between Malassezia colonization and increased IgE production in AD. It is possible that M. globosa and M. restricta play a synergistic role in triggering a Th2-shifted humoral immune response in AD. Another important connection between Malassezia colonization and $\mathrm{AD}$ relates to the increased secretion of granulocyte-macrophage colony-stimulating factor (GM-CSF) and cutaneous T-cellattracting chemokine (CTACK) by keratinocytes (Ishibashi et al. 2006). Malassezia globosa is capable of stimulating keratinocytes to secrete GM-CSF, which primarily contributes to the maintenance of the chronic inflammatory process in AD by enhancing the antigenpresenting capacity of Langerhans cells and dendritic cells (Witmer-Pack et al. 1987). Malassezia restricta induces the secretion of CTACK by keratinocytes. CTACK selectively attracts cutaneous lymphocyte antigen-positive memory $\mathrm{T}$ cells to inflammatory sites (Morales et al. 1999) and is upregulated in AD patients (Kakinuma et al. 2003). The above findings suggest the following possible mechanism by which Malassezia species induce an IgE-immune response in patients with AD: a skin barrier dysfunction facilitates skin penetration by colonized Malassezia, allowing interactions between Malassezia and epidermal Langerhans cells, dendritic cells, and keratinocytes, which subsequently present Malassezia antigens, thereby inducing an immune response. This may be augmented by keratinocyte-derived GM-CSF. Malassezia-stimulated keratinocytes produce Th2 cytokines, including IL-4 and IL-13, which may in turn stimulate B cells to undergo IgE class switching and produce Malassezia-specific IgE. In addition, keratinocyte-derived IL-5 may attract and locally activate eosinophils in lesions of AD.

\subsection{Malassezia allergens}

Many Malassezia allergens have been identified, including Mala f2-4, Mala s1, and Mala s5-13. Several researchers have attempted to produce recombinant Malassezia allergens (rMala s1 and rMala s5-11) for diagnostic purposes (Schmidt et al. 1997; Schmid-Grendelmeier et al. 2005, 2006; Limacher et al. 2007) (Table 2). Recently, proteomics analysis has been applied to identify major allergens of M. globosa (Ishibashi et al. 2009). The IgE-reactive component of M. globosa, with a molecular mass of $42 \mathrm{kDa}$ and designated as MGp42, has been identified by twodimensional immunoblotting and partially sequenced by matrix-assisted laser desorption ionization time of flight mass spectrometry with post-source decay of the peptide digest. The 
full-length cDNA encoding MGp42 has been cloned and sequenced by the rapid amplification of cDNA ends method. MGp42 exhibits properties similar to those of heat shock protein (hsp) family members, and evidence indicates that MGp42 may be a cleavage product of intact HSP70. However, no IgE cross-reactivity has been observed between MGp42 and recombinant human HSP70, suggesting that the epitopes of MGp42 recognized by serum IgE of $\mathrm{AD}$ patients are masked by steric hindrance in the presence of intact HSP70 and become exposed as a result of conformational changes during HSP70 cleavage.

\begin{tabular}{clll}
\hline Allergens & \multicolumn{1}{c}{ Function } & \multicolumn{1}{c}{ Species } & \multicolumn{1}{c}{ Reference } \\
\hline Mala s1 & Unknown & M. sympodialis & Schmidt et al. 1997 \\
Mala f2 & peroxisomal protein & M. furfur & Yasueda et al. 1998 \\
Mala f3 & peroxisomal protein & M. furfur & Yasueda et al. 1998 \\
Mala f4 & Malate dehydrogenase & M. furfur & Onishi et al. 1999 \\
Mala s5 & peroxisomal protein & M. sympodialis & Hemmann et al. 1997 \\
Mala s6 & Cyclophilin & M. sympodialis & Hemmann et al. 1997 \\
Mala s7 & Unknown & M. sympodialis & Weichel et al. 2002 \\
Mala s8 & Unknown & M. sympodialis & Weichel et al. 2002 \\
Mala s9 & Unknown & M. sympodialis & Weichel et al. 2002 \\
Mala s10 & Heat shock protein & M. sympodialis & Lindborg et al. 1999 \\
Mala s11 & MnSOD & M. sympodialis & Lindborg et al. 1999 \\
Mala s12 & GMC oxidoreductase & M. sympodialis & Rasool et al. 2000 \\
Mala s13 & Thioredoxin & M. sympodialis & Limacher et al. 2007 \\
MGp42 & Heat shock protein & M. globosa & Ishibashi et al. 2009 \\
\hline
\end{tabular}

Table 2. Malassezia allergens

\section{Treatment with antifungal agents}

\subsection{Anti-Malassezia IgE in the serum of AD patients}

Skin prick tests positive for Malassezia antigen and specific $\operatorname{IgE}$ antibodies have been demonstrated in head and neck AD (HANAD) patients. A delayed-type hypersensitivity to Malassezia antigen also seems to play a role. Of 33 HANAD patients, $79 \%$ were prick-test positive for Malassezia antigen, but only $44 \%$ of 22 AD patients without head and neck involvement were prick-test positive (Kieffer et al. 1990). Rokugo et al. (1990) found that $71 \%$ of 35 AD patients who were prick-test positive for Malassezia antigen also demonstrated delayed hypersensitivity to Malassezia antigen in $64 \%$ of 118 AD patients. The presence of antiMalassezia IgE antibody has been demonstrated in several studies (Table 3). The frequency of Malassezia specific IgE antibody in serum was higher in AD patients with head and neck dermatitis than without. For example, Bayrou et al. (2005) found IgE antibodies against Malassezia antigen in $100 \%$ of 106 HANAD patients, but in only $28 \%$ of 25 AD patients without head and neck involvement. Total IgE levels were also significantly higher in the AD group with head and neck dermatitis (mean, 2,823 kU/L) than without $(546 \mathrm{kU} / \mathrm{L})$. 


\begin{tabular}{lcc}
\hline \multicolumn{1}{c}{ Authors } & Patients & $\begin{array}{c}\text { Production of anti-Malassezia } \\
\text { specific IgE antibodies }\end{array}$ \\
\hline Devos and Valk, 2000 & HANAD & $100 \%(\mathrm{n}=22)$ \\
Johansson et al. 2003 & Non-HANAD & $14 \%(\mathrm{n}=22)$ \\
& HANAD & $55 \%(\mathrm{n}=98)$ \\
Jensen-Jarolim et al. 1992 & Non-HANAD & $19 \%(\mathrm{n}=33)$ \\
\hline
\end{tabular}

Table 3. Malassezia IgE antibodies in sera of patient with atopic dermatitis

There was also a significant correlation between the level of Malassezia specific IgE antibody and clinical severity criteria, as reflected by the SCORAD index $\left(p<0.0001, r^{2}=0.55\right)$, whereas total IgE showed only a slight correlation with severity criteria $\left(p<0.001, r^{2}=0.29\right)$. No correlation was found between age or gender, and specific or total IgE. Based on pricktest results and specific IgE antibody levels, treatment of HANAD patients with antifungal agents has been recommended for the previous two decades.

\subsection{Susceptibility of Malassezia to drug treatment}

Compared with the plethora of antibacterial agents, only a small number of antifungal agents are available, which limits the treatment options for HANAD. Ketoconazole and itraconazole are highly effective in vitro (Sugita et al. 2005, Miranda et al. 2007, Sancak et al. 2005, Velegraki et al. 2004). In a large-scale study using 125 strains of 11 Malassezia species, all of the Malassezia species were highly susceptible to both itraconazole and ketoconazole, with minimum inhibitory concentrations (MICs) ranging from 0.016 to $0.25 \mathrm{mg} / \mathrm{ml}$; approximately $80 \%$ of the strains had a MIC of $\leq 0.03 \mathrm{mg} / \mathrm{ml}$ (Sugita et al. (2005). This efficacy is not specific to these species, but applies to all members of the genus Malassezia. To our knowledge, no resistant strain has been detected. Ketoconazole and itraconazole are chemically classified as azole compounds, but other azole agents, fluconazole, voriconazole, and terbinafine, cannot inhibit the growth of Malassezia.

A calcineurin inhibitor, topical tacrolimus, is widely used to treat AD. This compound had antifungal activity against half of the known Malassezia strains, with MICs of $16-32 \mathrm{mg} / \mathrm{mL}$ (Sugita et al. 2005). The immunosuppressive drugs cyclosporine and tacrolimus target calcineurin and are also toxic to Candida albicans and Cryptococcus neoformans (Cruz et al. 2001). A combination of either ketoconazole or itraconazole and tacrolimus had a synergistic effect against Malassezia strains, based on a fractional inhibitory index of 0.245 to 0.378 . These observations follow earlier reports on the effectiveness of a combination of tacrolimus and fluconazole against $C$. albicans and C. neoformans strains. The combination of topical tacrolimus and an azole agent can simultaneously treat $\mathrm{AD}$ and reduce the number of exacerbating Malassezia cells colonizing the skin surface. Although the synergistic mechanism of this combination is not known, Maesaki et al. (1998) demonstrated that tacrolimus increases the intracellular concentration of the azole agent in $C$. albicans. This observation may provide the basis for future clinical trials of these agents aimed at reducing the number of Malassezia cells colonizing the skin of AD patients (more details are provided in the following section). 


\begin{tabular}{|c|c|c|c|c|}
\hline Authors & Drug & Study design & $\begin{array}{c}\text { Number of } \\
\text { patients }\end{array}$ & Dosage \\
\hline $\begin{array}{l}\text { Bäck et al. } \\
1995\end{array}$ & Ketoconazole & $\begin{array}{l}\text { Open-label } \\
\text { study }\end{array}$ & $\begin{array}{l}20 \text { AD patients } \\
\text { with positive } \\
\text { RAST to } \\
\text { Malassezia }\end{array}$ & $\begin{array}{l}200 \mathrm{mg} \text { daily for } 2 \text { months and } \\
200 \mathrm{mg} \text { twice weekly for } \\
\text { further } 3 \text { months. }\end{array}$ \\
\hline \multirow[t]{2}{*}{$\begin{array}{l}\text { Broberg and } \\
\text { Faergemann, } \\
1995\end{array}$} & $\begin{array}{l}\text { Ketoconazole } \\
\text { shampoo }\end{array}$ & $\begin{array}{l}\text { Randomized } \\
\text { double-blind } \\
\text { placebo- } \\
\text { controlled } \\
\text { study }\end{array}$ & $\begin{array}{l}53 \text { HANAD } \\
\text { patients }\end{array}$ & $\begin{array}{l}\text { Group A: miconazole- } \\
\text { hydrocortisone cream and } \\
\text { ketoconazole shampoo for } 6 \\
\text { weeks }\end{array}$ \\
\hline & & & & $\begin{array}{l}\text { Group B: hydrocortisone cream } \\
\text { and placebo shampoo for } 6 \\
\text { weeks }\end{array}$ \\
\hline \multirow[t]{2}{*}{$\begin{array}{l}\text { Bäck and } \\
\text { Bartosik, } \\
2001\end{array}$} & Ketoconazole & $\begin{array}{l}\text { Randomized } \\
\text { double-blind } \\
\text { placebo- } \\
\text { controlled } \\
\text { study }\end{array}$ & $\begin{array}{l}29 \text { HANAD } \\
\text { patients with } \\
\text { specific IgE } \\
\text { antibodies to } \\
\text { Malassezia }\end{array}$ & $\begin{array}{l}\text { Group A: } 200 \mathrm{mg} \text { ketoconazole } \\
\text { daily for } 3 \text { months }\end{array}$ \\
\hline & & & & Group B: placebo for 3 months \\
\hline \multirow[t]{2}{*}{$\begin{array}{l}\text { Ikezawa } \\
\text { et al. } 2004\end{array}$} & Itraconazole & $\begin{array}{l}\text { Randomized } \\
\text { double-blind } \\
\text { crossover } \\
\text { study }\end{array}$ & $\begin{array}{l}34 \text { AD patients } \\
\text { with positive } \\
\text { RAST to } \\
\text { Malassezia }\end{array}$ & $\begin{array}{l}\text { Group A: } 100 \mathrm{mg} \text { daily of } \\
\text { itraconazole and lactobacillus } \\
\text { preparation for } 8 \text { weeks and } \\
\text { lactobacillus preparation alone } \\
\text { for further } 8 \text { weeks }\end{array}$ \\
\hline & & & & $\begin{array}{l}\text { Group B: Lactobacillus } \\
\text { preparation alone for } 8 \text { weeks } \\
\text { and } 100 \mathrm{mg} \text { daily of itraconazole } \\
\text { and lactobacillus preparation } \\
\text { for additionally } 8 \text { weeks }\end{array}$ \\
\hline \multirow[t]{3}{*}{$\begin{array}{l}\text { Svejgaard } \\
\text { et al. } 2005\end{array}$} & Itraconazole & $\begin{array}{l}\text { Randomized } \\
\text { double-blind } \\
\text { placebo- } \\
\text { controlled } \\
\text { study }\end{array}$ & $\begin{array}{l}53 \text { HANAD } \\
\text { patients }\end{array}$ & $\begin{array}{l}\text { Group A: } 200 \mathrm{mg} \text { itraconazole } \\
\text { for } 7 \text { days }\end{array}$ \\
\hline & & & & $\begin{array}{l}\text { Group B: } 400 \mathrm{mg} \text { itraconazole } \\
\text { for } 7 \text { days }\end{array}$ \\
\hline & & & & Group C: placebo \\
\hline
\end{tabular}

Table 4. Treatment for ketoconazole or itraconazole in HANAD patients

\subsection{Ketoconazole and itraconazole in AD treatment (Table 4)}

A relationship between Malassezia and AD was first suggested by Clemmensen and Hjorth (1983), who demonstrated that oral ketoconazole was efficacious in adult HANAD patients with positive prick tests for Malassezia. A study of 20 AD patients with positive radioallergosorbent test results for Malassezia showed that treatment with oral ketoconazole 
improved clinical scores and reduced the levels of Malassezia specific IgE, particularly in the head and neck area (Bäck et al. 1995). However, in a double-blind study with 53 HANAD patients, no difference in the clinical score was detected between those treated with miconazole-hydrocortisone cream and ketoconazole shampoo and those treated with hydrocortisone cream and placebo shampoo, although the ketoconazole group showed decreased Malassezia colonization (Broberg and Faergemann 1995). In another randomized double-blind placebo-controlled study comparing treatment with $200 \mathrm{mg}$ ketoconazole daily versus placebo for 3 months in 29 HANAD patients with specific IgE antibodies to Malassezia, the clinical score decreased in both groups, and the improvement was correlated with the use of topical steroids in the control group, but not in the ketoconazole group (Bäck and Bartosik 2001).

A number of studies have also been conducted with itraconazole. In one study, 53 HANAD patients were divided into three groups that received $200 \mathrm{mg}$ itraconazole, $400 \mathrm{mg}$ itraconazole, or placebo daily (Svejgaard et al. 2004). The study included a 7-day treatment period and a follow-up period of 105 days. At days 7 and 14, a significant improvement was observed in the SCORAD of the head and neck area in the groups given 400 and $200 \mathrm{mg}$ itraconazole daily. At day 14, a comparison among all three groups showed a significant improvement in the SCORAD of the head and neck area in the $200 \mathrm{mg}$ itraconazole group compared with the placebo group. A randomized double-blind crossover study was also conducted (Ikezawa et al. 2004). One group was treated with a combination of itraconazole (100 mg daily) plus a conventional Lactobacillus preparation for 8 weeks, followed by the Lactobacillus preparation alone for 8 weeks. The other group received the Lactobacillus preparation alone for 8 weeks, followed by itraconazole (100 $\mathrm{mg}$ daily) plus Lactobacillus for 8 weeks. In both groups, a decrease in the dose or strength of concomitant topical steroids was observed at the end of the treatment course with itraconazole, and improvements in the eosinophil count, serum $\operatorname{IgE}$, and fungi-specific IgE were found after the administration of itraconazole.

Itraconazole appears to be a promising treatment option for HANAD patients who do not respond to conventional therapeutic approaches. To optimize the selection of patients most likely to respond to itraconazole treatment, the levels of Malassezia colonization of the skin and specific IgE antibody should be evaluated.

\section{Acknowledgment}

This study was supported in part by a research grant from the Japan Society for the Promotion of Science (TS), a research grant for "High-Tech Research Center Project" from the Ministry of Education, Culture, Sports, Science, and Technology (TS).

\section{References}

Albanesi C, Scarponi C, Giustizieri ML, Girolomoni G. 2005, Keratinocytes in inflammatory skin diseases. Curr Drug Targets Inflamm Allergy. 4, 329-334.

Amaya M, Tajima M, Okubo Y, Sugita T, Nishikawa A, Tsuboi R. 2007, Molecular analysis of Malassezia microflora in the lesional skin of psoriasis patients. J Dermatol. 34, 619-624.

Ashbee HR. 2007, Update on the genus Malassezia. Med Mycol. 45, 287-303. 
Bäck O, Scheynius A, Johansson SG. 1995, Ketoconazole in atopic dermatitis: therapeutic response is correlated with decrease in serum IgE. Arch Dermatol Res. 287, 448-451.

Bäck O, Bartosik J. 2001, Systemic ketoconazole for yeast allergic patients with atopic dermatitis. J Eur Acad Dermatol Venereol 15, 34-38.

Bayrou O, Pecquet C, Flahault A, Artigou C, Abuaf N, Leynadier F. 2005, Head and neck atopic dermatitis and malassezia-furfur-specific IgE antibodies. Dermatology 211, 107-113.

Broberg A, Faergemann J. 1995, Topical antimycotic treatment of atopic dermatitis in the head/neck area. A double-blind randomised study. Acta Derm Venereol. 75, 46-49.

Chen L, Martinez O, Overbergh L, Mathieu C, Prabhakar BS, Chan LS. 2004, Early upregulation of Th2 cytokines and late surge of Th1 cytokines in an atopic dermatitis model. Clin Exp Immunol. 138, 375-387.

Clemmensen OJ, Hjorth N. 1983, Treatment of dermatitis of head and neck with ketoconazole in patients with type 1 sensitivity to Pityrosporum orbiculare. Semin. Dermatol. 2, 26-29.

Cruz M C, A L Goldstein, J Blankenship, M Del Poeta, J R Perfect, J H McCusker, Y L Bennani, M E Cardenas, J Heitman. 2001. Rapamycin and less immunosuppressive analogs are toxic to Candida albicans and Cryptococcus neoformans via FKBP12dependent inhibition of TOR. Antimicrob. Agents Chemother. 45, 3162-3170.

Devos SA, van der Valk PG. 2000, The relevance of skin prick tests for Pityrosporum ovale in patients with head and neck dermatitis. Allergy. 55, 1056-1058.

Esche C, de Benedetto A, Beck LA. 2004, Keratinocytes in atopic dermatitis. inflammatory signals. Curr Allergy Asthma Rep. 4, 276-284.

Grone, A. 2002, Keratinocytes and cytokines. Vet Immunol Immunopathol. 88, 1-12.

Guého-Kellermann E, Boekhout T, Begerow D. 2010, Biodiversity, Phylogeny and Ultrastructure. In Malassezia and the skin. Edited by Boekhout, Guého-Kellermann E, Mayser P, and Velegraki A, pp. 17-64, Springer, 2010.

Gupta AK, Kohli Y, Summerbell RC, Faergemann J. 2001, Quantitative culture of Malassezia species from different body sites of individuals with or without dermatoses. Med Mycol. 39, 243-251.

Gupta AK, Batra R, Bluhm R, Boekhout T, Dawson TL Jr. 2004, Skin diseases associated with Malassezia species. J Am Acad Dermatol. 51, 785-798.

Hamid Q, Boguniewicz M, Leung DY. 1994, Differential in situ cytokine gene expression in acute versus chronic atopic dermatitis. J Clin Invest. 94, 870-876.

Hemmann S, Blaser K, Crameri R. 1997, Allergens of Aspergillus fumigatus and Candida boidinii share IgE-binding epitopes. Am J Respir Crit Care Med. 156, 1956-1962.

Higaki S, Morohashi M, Yamagishi T, Hasegawa Y. 1999, Comparative study of staphylococci from the skin of atopic dermatitis patients and from healthy subjects. Int J Dermatol. 38, 265-269.

Hoeger PH, Lenz W, Boutonnier A, Fournier JM. 1992, Staphylococcal skin colonization in children with atopic dermatitis: prevalence, persistence, and transmission of toxigenic and nontoxigenic strains. J Infect Dis. 165, 1064-1068.

Howell MD. 2007, The role of human beta defensins and cathelicidins in atopic dermatitis. Curr Opin Allergy Clin Immunol. 7, 413-417. 
Ikezawa Z, Kondo M, Okajima M, Nishimura Y, Kono M. 2004, Clinical usefulness of oral itraconazole, an antimycotic drug, for refractory atopic dermatitis. Eur J Dermatol. 14, 400-406.

Ishibashi Y Sugita T Nishikawa A. 2006, Cytokine secretion profile of human keratinocytes exposed to Malassezia yeasts. FEMS Immunol Med Microbiol. 48, 400-409.

Ishibashi Y, Kato H, Asahi Y, Sugita T, Nishikawa A. 2009, Identification of the major allergen of Malassezia globosa relevant for atopic dermatitis. J Dermatol. Sci. 55, 185-192.

Jensen-Jarolim E, Poulsen LK, With H, Kieffer M, Ottevanger V, Stahl Skov P. 1992, Atopic dermatitis of the face, scalp, and neck: type I reaction to the yeast Pityrosporum ovale? J Allergy Clin Immunol. 89, 44-51.

Johansson C, Sandström MH, Bartosik J, Särnhult T, Christiansen J, Zargari A, Bäck O, Wahlgren CF, Faergemann J, Scheynius A, Tengvall Linder M. 2003, Atopy patch test reactions to Malassezia allergens differentiate subgroups of atopic dermatitis patients. Br J Dermatol 148, 479-488.

Kaga M, Sugita T, Nishikawa A, Wada Y, Hiruma M, Ikeda S. 2011, Molecular analysis of the cutaneous Malassezia microbiota from the skin of patients with atopic dermatitis of different severities. Mycoses 54, e24-28.

Kakinuma T, Saeki H, Tsunemi Y, Fujita H, Asano N, Mitsui H, Tada Y, Wakugawa M, Watanabe T, Torii H, Komine M, Asahina A, Nakamura K, Tamaki K. 2003, Increased serum cutaneous $\mathrm{T}$ cell-attracting chemokine (CCL27) levels in patients with atopic dermatitis and psoriasis vulgaris. J Allergy Clin Immunol. 111, 592-597.

Kaneko T, Makimura K, Abe M, Shiota R, Nakamura Y, Kano R, Hasegawa A, Sugita T, Shibuya S, Watanabe S, Yamaguchi H, Abe S, Okamura N. 2007, Revised culturebased system for identification of Malassezia species. J Clin Microbiol. 45, 3737-3742.

Kato H, Sugita T, Ishibashi Y, Nishikawa A. 2006, Detection and quantification of specific IgE antibodies against eight Malassezia species in sera of patients with atopic dermatitis by using an enzyme-linked immunosorbent assay. Microbiol Immunol. 50, 851-856.

Kieffer M, Bergbrant I-M, Faergeman J, Jemec GBE, Ottevanger V, Skov PS, Svejgaard E. 1990, Immune reactions to Pityrosporum ovale in adult patients with atopic and seborrhoeic dermatitis. J. Am. Acad. Dermatol. 22, 739-742.

Leung DY. 2000, Atopic dermatitis. new insights and opportunities for therapeutic intervention. J Allergy Clin Immunol. 105, 860-876.

Limacher A, Glaser AG, Meier C, Schmid-Grendelmeier P, Zeller S, Scapozza L, Crameri R. 2007, Cross-reactivity and 1.4-A crystal structure of Malassezia sympodialis thioredoxin (Mala s 13), a member of a new pan-allergen family. J Immunol 178, 389-396.

Lindborg M, Magnusson CG, Zargari A, Schmidt M, Scheynius A, Crameri R, Whitley P. 1999, Selective cloning of allergens from the skin colonizing yeast Malassezia furfur by phage surface display technology. J Invest Dermatol 113, 156-161.

Maesaki S, P Marichal, M A Hossain, D Sanglard, H Vanden Bossche, S Kohno. 1998, Synergic effects of tactolimus and azole antifungal agents against azole-resistant Candida albican strains. J. Antimicrob. Chemother. 42, 747-753.

Miranda KC, de Araujo CR, Costa CR, Passos XS, de Fátima Lisboa Fernandes O, do Rosário Rodrigues Silva M. 2007, Antifungal activities of azole agents against the Malassezia species. Int J Antimicrob Agents. 29, 281-284. 
Morales J, Homey B, Vicari AP, Hudak S, Oldham E, Hedrick J, Orozco R, Copeland NG, Jenkins NA, McEvoy LM, Zlotnik A. 1999, CTACK, a skin-associated chemokine that preferentially attracts skin-homing memory T cells. Proc Natl Acad Sci USA 96, 14470-14475.

Morishita N, Sei Y, Sugita T. 2006, Molecular analysis of malassezia microflora from patients with pityriasis versicolor. Mycopathologia 161, 61-65.

Nakabayashi A, Sei Y, Guillot J. 2000, Identification of Malassezia species isolated from patients with seborrhoeic dermatitis, atopic dermatitis, pityriasis versicolor and normal subjects. Med Mycol. 38, 337-341.

Onishi Y, Kuroda M, Yasueda H, Saito A, Sono-Koyama E, Tunasawa S, Hashida-Okado T, Yagihara T, Uchida K, Yamaguchi H, Akiyama K, Kato I, Takesako K. 1999, Twodimensional electrophoresis of Malassezia allergens for atopic dermatitis and isolation of Mal f 4 homologs with mitochondrial malate dehydrogenase. Eur J Biochem. 261, 148-154.

Rasool O, Zargari A, Almqvist J, Eshaghi H, Whitley P, Scheynius A. 2000, Cloning, characterization and expression of complete coding sequences of three IgE binding Malassezia furfur allergens, Mal f 7, Mal f 8 and Mal f 9. Eur J Biochem 267, 4355-4361.

Rokugo M, Tagami H, Usuba Y, Tomita Y. 1990, Contact sensitivity to Pityrosporum ovale in patients with an atopic dermatitis. Arch. Dermatol. 126, 627-634.

Sancak B, Ayhan M, Karaduman A, Arikan S. 2005, In vitro activity of ketoconazole, itraconazole and terbinafine against Malassezia strains isolated from neonates. Mikrobiyol Bul. 39, 301-308. Turkish.

Sandström Falk MH, Tengvall Linder M, Johansson C, Bartosik J, Bäck O, Särnhult T, Wahlgren CF, Scheynius A, Faergemann J. 2005, The prevalence of Malassezia yeasts in patients with atopic dermatitis, seborrhoeic dermatitis and healthy controls. Acta Derm Venereol. 85, 17-23.

Schmidt M, Zargari A, Holt P, Lindbom L, Hellman U, Whitley P, van der Ploeg I, Härfast B, Scheynius A. 1997, The complete cDNA sequence and expression of the first major allergenic protein of Malassezia furfur, Mal f 1. Eur J Biochem 246, 181-185.

Schmid-Grendelmeier P, Flückiger S, Disch R, Trautmann A, Wüthrich B, Blaser K, Scheynius A, Crameri R. 2005, IgE-mediated and T cell-mediated autoimmunity against manganese superoxide dismutase in atopic dermatitis. J Allergy Clin Immunol 115, 1068-1075.

Schmid-Grendelmeier P, Scheynius A, Crameri R. 2006, The role of sensitization to Malassezia sympodialis in atopic eczema. Chem Immunol Allergy 91, 98-109.

Seidenari S, Giusti G. 1995, Objective assessment of the skin of children affected by atopic dermatitis: a study of $\mathrm{pH}$, capacitance and TEWL in eczematous and clinically uninvolved skin. Acta Derm Venereol. 75, 429-433.

Sugita T, Suto H, Unno T, Tsuboi R, Ogawa H, Shinoda T, Nishikawa A. 2001, Molecular analysis of Malassezia microflora on the skin of atopic dermatitis patients and healthy subjects. J Clin Microbiol. 39, 3486-3490.

Sugita T, Kodama M, Saito M, Ito T, Kato Y, Tsuboi R, Nishikawa A. 2003, Sequence diversity of the intergenic spacer region of the rRNA gene of Malassezia globosa colonizing the skin of patients with atopic dermatitis and healthy individuals. J Clin Microbiol. 41, 3022-3027. 
Sugita T, Tajima M, Amaya M, Tsuboi R, Nishikawa A. 2004, Genotype analysis of Malassezia restricta as the major cutaneous flora in patients with atopic dermatitis and healthy subjects. Microbiol Immunol. 48, 755-759.

Sugita T, Tajima M, Ito T, Saito M, Tsuboi R, Nishikawa A. 2005, Antifungal activities of tacrolimus and azole agents against the eleven currently accepted Malassezia species. J Clin Microbiol. 43, 2824-2829.

Sugita T, Tajima M, Tsubuku H, Tsuboi R, Nishikawa A. 2006a, Quantitative analysis of cutaneous Malassezia in atopic dermatitis patients using real-time PCR. Microbiol Immunol. 50, 549-552.

Sugita T, Boekhout T, Velegraki A, Guillot J, Hadina S, Cabanes FJ. 2010, Epidemiology of Malassezia-related skin diseases. In Malassezia and the skin. Edited by Boekhout, Guého-Kellermann E, Mayser P, and Velegraki A, pp. 65-120, Springer, 2010.

Sugita T, Zhang E, Miyamoto M, Tajima M, Tsuboi R, Nishikawa A. 2011, Chapter 73 Malassezia, In Molecular Detection of Human Fungal Pathogens. Edited by Dongyou Liu, Taylor \& Francis Group. 631-638.

Svejgaard E, Larsen PØ, Deleuran M, Ternowitz T, Roed-Petersen J, Nilsson J. 2004, Treatment of head and neck dermatitis comparing itraconazole $200 \mathrm{mg}$ and $400 \mathrm{mg}$ daily for 1 week with placebo. J Eur Acad Dermatol Venereol. 18, 445-449.

Tajima M, Sugita T, Nishikawa A, Tsuboi R. 2008, Molecular analysis of Malassezia microflora in seborrheic dermatitis patients: comparison with other diseases and healthy subjects. J Invest Dermatol. 128, 345-351.

Takahata Y, Sugita T, Hiruma M, Muto M. 2007a, Quantitative analysis of Malassezia in the scale of patients with psoriasis using a real-time polymerase chain reaction assay. Br J Dermatol. 157, 670-673.

Takahata Y, Sugita T, Kato H, Nishikawa A, Hiruma M, Muto M. 2007b, Cutaneous Malassezia flora in atopic dermatitis differs between adults and children. $\mathrm{Br} J$ Dermatol. 157, 1178-1182.

Velegraki A, Alexopoulos EC, Kritikou S, Gaitanis G. 2004, Use of fatty acid RPMI 1640 media for testing susceptibilities of eight Malassezia species to the new triazole posaconazole and to six established antifungal agents by a modified NCCLS M27A2 microdilution method and Etest. J Clin Microbiol. 42, 3589-3593.

Watanabe S, Kano R, Sato H, Nakamura Y, Hasegawa A. 2001, The effects of Malassezia yeasts on cytokine production by human keratinocytes. J Invest Dermatol. 116, 769-773.

Weichel M, Fluckiger S, Crameri R. 2002. Molecular characterization of mould allergens involved in respiratory complications. Rencet Res devel Resp Critical Care Med. 2, 29-45.

Witmer-Pack MD, Olivier W, Vaiinsky J. 1987, Granulocyte-macrophage colony-stimulating factor is essential for the viability and function of cultured murine epidermal Langerhans cells. J Exp Med. 166, 1484-1498.

Xu J, Saunders CW, Hu P, Grant RA, Boekhout T, Kuramae EE, Kronstad JW, Deangelis YM, Reeder NL, Johnstone KR, Leland M, Fieno AM, Begley WM, Sun Y, Lacey MP, Chaudhary T, Keough T, Chu L, Sears R, Yuan B, Dawson TL Jr. 2007, Dandruffassociated Malassezia genomes reveal convergent and divergent virulence traits shared with plant and human fungal pathogens. Proc Natl Acad Sci U S A. 104, 18730-18735. 
Yamamoto A, Serizawa S, Ito M, Sato Y. 1991, Stratum corneum lipid abnormalities in atopic dermatitis. Arch Dermatol Res. 283, 219-223.

Yasueda H, Hashida-Okado T, Saito A, Uchida K, Kuroda M, Onishi Y, Takahashi K, Yamaguchi H, Takesako K, Akiyama K. 1998. Identification and cloning of two novel allergens from the lipophilic yeast, Malassezia furfur. Biochem Biophys Res Commun. 248, 240-244.

Zargari A, Midgley G, Bäck O, Johansson SG, Scheynius A. 2003, IgE-reactivity to seven Malassezia species. Allergy 58, 306-311.

Zhang E, Tanaka T, Tajima M, Tsuboi R, Nishikawa A, Sugita T. 2011, Characterization of the skin fungal microbiota in patients with atopic dermatitis and healthy subjects. Microbiol Immunol Jun 24. doi: 10.1111/j.1348-0421.2011.00364.x. [Epub ahead of print] 


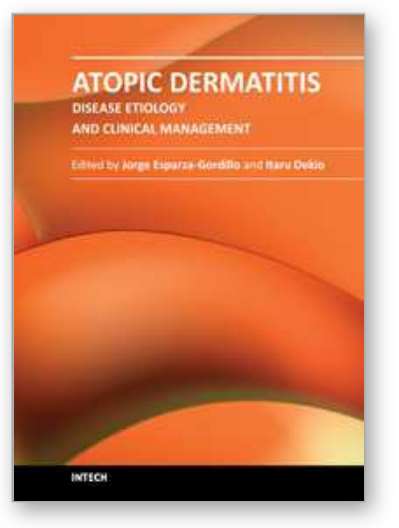

\author{
Atopic Dermatitis - Disease Etiology and Clinical Management \\ Edited by Dr. Jorge Esparza-Gordillo
}

ISBN 978-953-51-0110-9

Hard cover, 414 pages

Publisher InTech

Published online 22, February, 2012

Published in print edition February, 2012

Atopic Dermatitis is a common disease characterized by inflamed, itching and dry skin. This relapsing allergic disorder has complex etiology and shows a remarkably high clinical heterogeneity which complicates the diagnosis and clinical management. This book is divided into 4 sections. The first section (Disease Etiology) describes some of the physiological mechanisms underlying Atopic Dermatitis, including alterations in the immune system and the skin-barrier function. The important role of host-microorganism interactions on the pathophysiology of Atopic Dermatitis is discussed in the second section (Microorganisms in Atopic Dermatitis). An overview of the clinical diagnostic criteria and the disease management protocols commonly used is given in the third section (Diagnosis and Clinical Management). The last section (New Treatments) describes new therapeutic approaches that are not widely used but are currently being studied due to preliminary evidence showing a clinical benefit for Atopic Dermatitis.

\title{
How to reference
}

In order to correctly reference this scholarly work, feel free to copy and paste the following:

Takashi Sugita, Enshi Zhang, Takafumi Tanaka, Mami Tajima, Ryoji Tsuboi, Yoshio Ishibashi, Akemi Nishikawa (2012). Atopic Dermatitis and Skin Fungal Microorganisms, Atopic Dermatitis - Disease Etiology and Clinical Management, Dr. Jorge Esparza-Gordillo (Ed.), ISBN: 978-953-51-0110-9, InTech, Available from: http://www.intechopen.com/books/atopic-dermatitis-disease-etiology-and-clinical-management/atopicdermatitis-and-skin-fungal-microorganisms

\section{INTECH}

open science | open minds

\section{InTech Europe}

University Campus STeP Ri

Slavka Krautzeka 83/A

51000 Rijeka, Croatia

Phone: +385 (51) 770447

Fax: +385 (51) 686166

www.intechopen.com

\section{InTech China}

Unit 405, Office Block, Hotel Equatorial Shanghai

No.65, Yan An Road (West), Shanghai, 200040, China

中国上海市延安西路65号上海国际贵都大饭店办公楼405单元

Phone: +86-21-62489820

Fax: $+86-21-62489821$ 
(C) 2012 The Author(s). Licensee IntechOpen. This is an open access article distributed under the terms of the Creative Commons Attribution 3.0 License, which permits unrestricted use, distribution, and reproduction in any medium, provided the original work is properly cited. 